\title{
ENTRAVES E SOLUÇÕES DA COMERCIALIZAÇÃO: RESULTADOS DO MÉTODO ÍNDICE UFSCAR PARA O PDS/ASSENTAMENTO SANTA HELENA, SÃO CARLOS /SP/BRASIL
}

\author{
Terezinha Pinto de Arruda ${ }^{D} 1$; Luiz Manoel de Moraes Camargo Almeida (D)2 \\ Daiane Roncato Cardozo ${ }^{D} 3$; Vera Lúcia Silveira Botta Ferrante iD 4
}

Resumo: Este artigo avaliou as condições de Segurança Alimentar e Nutricional (SAN) ampla de agricultores familiares do Projeto de Desenvolvimento Sustentável (PDS)/Assentamento Santa Helena, pelos métodos da Escala Brasileira de Insegurança Alimentar (EBIA) e do Índice da Universidade Federal de São Carlos (UFSCar). Utilizou-se de formulários semiestruturados e percepções anotadas em caderno de campo para ampliar a lente qualitativa. Os resultados apontam a prevalência de segurança alimentar $(57,14 \%)$ e de insegurança alimentar $(42,86 \%)$ nas famílias obtidas pela EBIA, sendo que o PDS, como um todo, foi caracterizado pelo Índice UFSCar, com um índice moderado de SAN. Finalmente, requerem uma continuidade de políticas públicas voltadas as questões de produção sustentáveis de de canais de comercialização instituicionais e territoriais para melhoria da SAN da famílias assentadas.

Palavras-chave: EBIA; Índice UFSCar; Políticas Públicas; Projeto de Desenvolvimento Sustentável; Canais de comercialização.

\section{COMMERCIALIZATION OBSTACLES AND SOLUTIONS: RESULTS SO METHOD UFSCAR INDEX FOR PDS/SETTING SANTA HELENA, SÃO CARLOS /SP/BRAZIL}

\begin{abstract}
This article evaluated the conditions of Food and Nutritional Security (SAN) of family farmers in the Sustainable Development Project (PDS)/Santa Helena Settlement, using the methods of the Brazilian Scale of Food Insecurity (EBIA) and the Index of the Federal University of São Carlos (UFSCar). Semistructured forms and perceptions noted in a field notebook were used to

\footnotetext{
${ }^{1}$ Funcionária da EMBRAPA/São Carlos. Doutoranda no Programa de Pós-Graduação em Desenvolvimento Territorial e Meio Ambiente da Universidade de Araraquara/SP (UNIARA). Email: terezinha.arruda@embrapa.br.

${ }^{2}$ Doutor em Sociologia pela Universidade Estadual Paulista Júlio de Mesquita Filho (UNESP). Docente do Programa de Pós-Graduação em Desenvolvimento Territorial e Meio Ambiente da Universidade de Araraquara/SP (UNIARA). Professor Associado 3 do Centro de Ciências da Natureza do Campus Lagoa do Sino da Universidade Federal de São Carlos (UFSCar)E-mail: manoel77@yahoo.com.br.

${ }^{3}$ Doutora em Desenvolvimento Territorial e Meio Ambiente pela Universidade de Araraquara/SP (UNIARA). Docente na Faculdade de Tecnologia do Estado de São Paulo (FATEC). E-mail. daianecardozo@msn.com.

${ }^{4}$ Doutora em Sociologia pela Universidade Estadual Paulista Júlio de Mesquita Filho (UNESP). Coordenadora do Programa de Pós-graduação em Desenvolvimento Territorial e Meio Ambiente da Universidade de Araraquara/SP (UNIARA). E-mail: vbotta@techs.com.br.
} 
expand the qualitative lens. The results show the prevalence of food security $(57.14 \%)$ and food insecurity $(42.86 \%)$ in families obtained by the EBIA, and the PDS, as a whole, was characterized by the UFSCar Index, with a moderate index of SAN. Finally, they require a continuity of public policies aimed at issues of sustainable production of institutional and territorial marketing channels to improve the SAN of settled families.

Keywords: EBIA; UFSCar Index. Public policy; Sustainable Development Project; Marketing channels.

\section{Introdução}

A Segurança Alimentar e Nutricional (SAN) é um conceito amplo que vem sendo construído sob diversos aspectos, no anseio de ações efetivas por muitos países no combate à fome e à má nutrição relacionada ao excesso de peso (BRASIL, 2011). De acordo com Almeida et al. (2006), as políticas de SAN devem responder por quatro dimensões: produção, distribuição, acesso e consumo de alimentos, bem como devem estar ligadas a cinco eixos ou valores fundamentais da população: saúde, higiene, meio ambiente, autenticidade e solidariedade.

Nos países desenvolvidos, a Insegurança Alimentar (IA) é mais determinada por fatores relacionados à saúde (doenças), ingestão alimentar e estado nutricional do que por fatores socioeconômicos, como ocorre em países menos desenvolvidos (CARDOZO, 2016). No Brasil, 22\% da população encontra-se em situação de insegurança alimentar, o que representa cerca de 65 mil domicílios, registrados na Pesquisa Nacional por Amostra de Domicílios (PNAD) do Instituto Brasileiro de Geografia e Estatística (IBGE, 2013). Estudos mostram que a prevalência de IA, principalmente na área urbana, está associada às vulnerabilidades e aos riscos sociais sobre as condições de vida dessa população, principalmente em relação à renda, escolaridade, trabalho e saneamento básico (CARDOZO, 2016).

No meio rural, onde está presente a política de Reforma Agrária (RA), ainda que com retrocessos e sem mudar a elevada concentração fundiária brasileira, pesquisas buscam apontar a situação de SAN das famílias diante das efetividades e entraves encontrados na área.

O primeiro Relatório da Organização das Nações Unidas para Agricultura e Alimentação no Brasil (FAO, 2014), que apresenta o estado de SAN no país, reuniu informações e evidências de diversas fontes e setores para retratar esta situação, especialmente no decorrer dos anos de 2003 a 2013. Apontou situações críticas e atuais do país, tais como: o enfrentamento da vulnerabilidade crônica dos povos e comunidades tradicionais; a solução da principal questão agrária que é o acesso à terra; esforços para melhorar o equilíbrio entre modelos de produção agrícola do ponto de vista da SAN (transição da agricultura convencional para a agroecológica); a instituição de políticas de abastecimento; o incremento de acesso à água; e o combate ao excesso de peso (sobrepeso e obesidade) aliado à promoção da alimentação saudável. 
Os trabalhos de Guerrero (2009-2014) evidenciam a promoção da SAN por meio da política de RA com o fortalecimento da produção, o aumento de renda, a melhoria na qualidade de vida, o resgate de direitos e dignidade, no entanto, para maior efetividade, diferentes caminhos devem ser traçados e novas parcerias necessitam ser consolidadas. O trabalho da autora resulta de seis anos do acompanhamento das famílias de um assentamento do interior paulista e teve como um de seus principais objetivos, analisar a inter-relação dos diferentes aspectos da RA com a IA, sob o enfoque de uma metodologia de avaliação de SAN, a Escala Brasileira de Insegurança Alimentar (EBIA).

A EBIA é o método utilizado para avaliar a percepção da IA (acesso e disponibilidade de alimentos) em ambientes populacionais, inquirindo o responsável pelo alimento no domicílio sobre uma série de questões subjetivas e classificando as famílias em estado de segurança alimentar (SA) ou IA, em diferentes níveis. É amplamente utilizada no País devido ao baixo custo e de sua consistência interna e externa, porém, pode ser aperfeiçoada com a inclusão de outros indicadores, além da necessidade de sua aplicação local (CARDOZO, 2016). Algumas instituições estão buscando investir em estudos no aprimoramento da escala, como o caso da Universidade Federal de São Carlos (UFSCar), que criou um índice a partir de um conjunto de variáveis relacionadas à SAN dos agricultores familiares (ALMEIDA et al., 2015).

Em 1997, durante a Conferência de Roma para Agricultura e Alimentação, a Cúpula Mundial da Alimentação (uma arena de representação dos governos dos países vinculados a FAO/ONU) finalmente conseguiu produzir, em consenso, um conceito de segurança alimentar amplo para subsidiar políticas aplicáveis nos mais diversos países (desenvolvidos e subdesenvolvidos), baseado em cinco grandes eixos:

1) Saúde: relaciona-se à composição nutricional dos alimentos em suas dimensões dietéticas e farmacêuticas, exigindo a educação alimentar das camadas mais carentes da população;

2) Higiene: também relacionado à seguridade dos alimentos, que significa ausência de agrotóxicos, proporcionando alimentos seguros e saudáveis;

3) Ecológico ou orgânico: refere-se à produção de alimentos sem riscos tóxicos, com forte apelo de respeito ao meio ambiente, relevando-se a qualidade dos alimentos quanto à forma de sua produção (agroecológico ou orgânico), hábitos crescentes nas populações, especialmente nos países desenvolvidos;

4) Autenticidade: é o saber fazer, valorização da forma de produção tradicional, quanto da origem dos alimentos, com as devidas especificações dos processos produtivos agrícolas e agroindustriais (desde a utilização correta da terra até a forma de processamento);

5) Solidariedade: os valores morais ao consumo consciente e de agregação de valor aos produtos agrícolas social e ecologicamente corretos, advindos de assentamentos rurais ou de pequenas propriedades e sem utilização de mão de obra infantil.

No Brasil, desde os tempos coloniais havia uma preocupação por parte dos governantes com a alimentação da população. Essa preocupação termina 
por se focar nos estudos de SA e se transformar em políticas públicas a partir do século XX (BELIK, 2003). Desde então, esforços de vários governos no Brasil (locais, estaduais e federais) produziram a efetivação de políticas de SA (ALMEIDA, 2008).

No caso deste trabalho, pioneiro em analisar questões de SAN em um assentamento na modalidade de Projeto de Desenvolvimento Sustentável (PDS), criada pelo Instituto de Colonização Agrária (INCRA), em 1999, localizado no interior paulista, a problematização se baseia na necessidade de diagnosticar as dificuldades amplas relacionadas à SAN, enfrentadas pelos pequenos produtores e o processo contínuo de adequação às novas demandas que surgem e que têm que atender aos moldes exigidos para um PDS.

Pesquisas realizadas anteriormente neste universo empírico, abordaram questões relacionadas a problemas socioambientais através de técnicas agroecológicas (SILVA et al., 2015; LOPES, 2014; SARAVALLE et al., 2016). Assim, este estudo de caso buscou complementar a avaliação deste universo com pesquisas voltadas a diferentes aspectos da SAN (sociais e econômicas, hábitos alimentares, entre outros) de produtores familiares assentados, por meio de metodologias atuais de avaliação para a promoção da SAN dessas famílias.

Nesse sentido, o objetivo central deste estudo de caso foi avaliar as condições sociodemográficas, socioeconômicas, ambientais e de SAN dos agricultores familiares do PDS Assentamento Santa Helena, localizado ao norte do município de São Carlos/SP. Dentro do objetivo central, destacaram-se como objetivos específicos: a caracterização das condições sociodemográficas, socioeconômicas, ambientais e de SAN das famílias de agricultores familiares, por meio de indicadores relacionados à renda, trabalho, moradia, assistência social, educação, saúde, diversificação da produção, autoconsumo, disponibilidade e acesso ao alimento, entre outros; a classificação da SA e da IA das famílias pela EBIA; e a mensuração e categorização da SAN pelo Índice UFSCar.

\section{Metodologia}

\subsection{Universo da pesquisa}

O município de São Carlos está localizado na Região Administrativa Central do Estado de São Paulo (RA12). Segundo o IBGE (2016), em 2010, a população era de 221.936 habitantes, sendo destes, 213.070 de população urbana e 8.866 da área rural. Em vista do crescimento imobiliário e melhor valorização da mão de obra para a construção civil, hoje, a população estimada é de 243.765 habitantes.

A pesquisa foi realizada no PDS Santa Helena, antes Fazenda Santa Helena, de propriedade da União que a transferiu para o INCRA, do Ministério do Desenvolvimento Agrário (MDA), para fins de RA. Apresenta uma área total de 98 ha, localizado na região denominada "Represa do 29" (Figura 1), vizinho ao Condomínio de Chácaras "Concórdia", sendo que um dos lotes está localizado às margens do Córrego do Quilombo, tendo em seu entorno a 
monocultura de cana-de-açúcar nos moldes convencionais, com uso de agrotóxicos. E até o final de 2016, tinha 14 famílias devidamente assentadas pelo Programa de Assentamentos Rurais.

Sendo o PDS uma modalidade de assentamento criada pelo INCRA para atender prioritariamente ao Plano Nacional de Reforma Agrária (PNRA) e aos anseios dos movimentos sociais do Brasil pela luta da terra, bem, como para o desenvolvimento de atividades ambientalmente diferenciadas, destinadas às populações que baseiam sua subsistência no extrativismo, na agricultura familiar e em outras atividades de baixo impacto ambiental (ALY JÚNIOR, 2011).

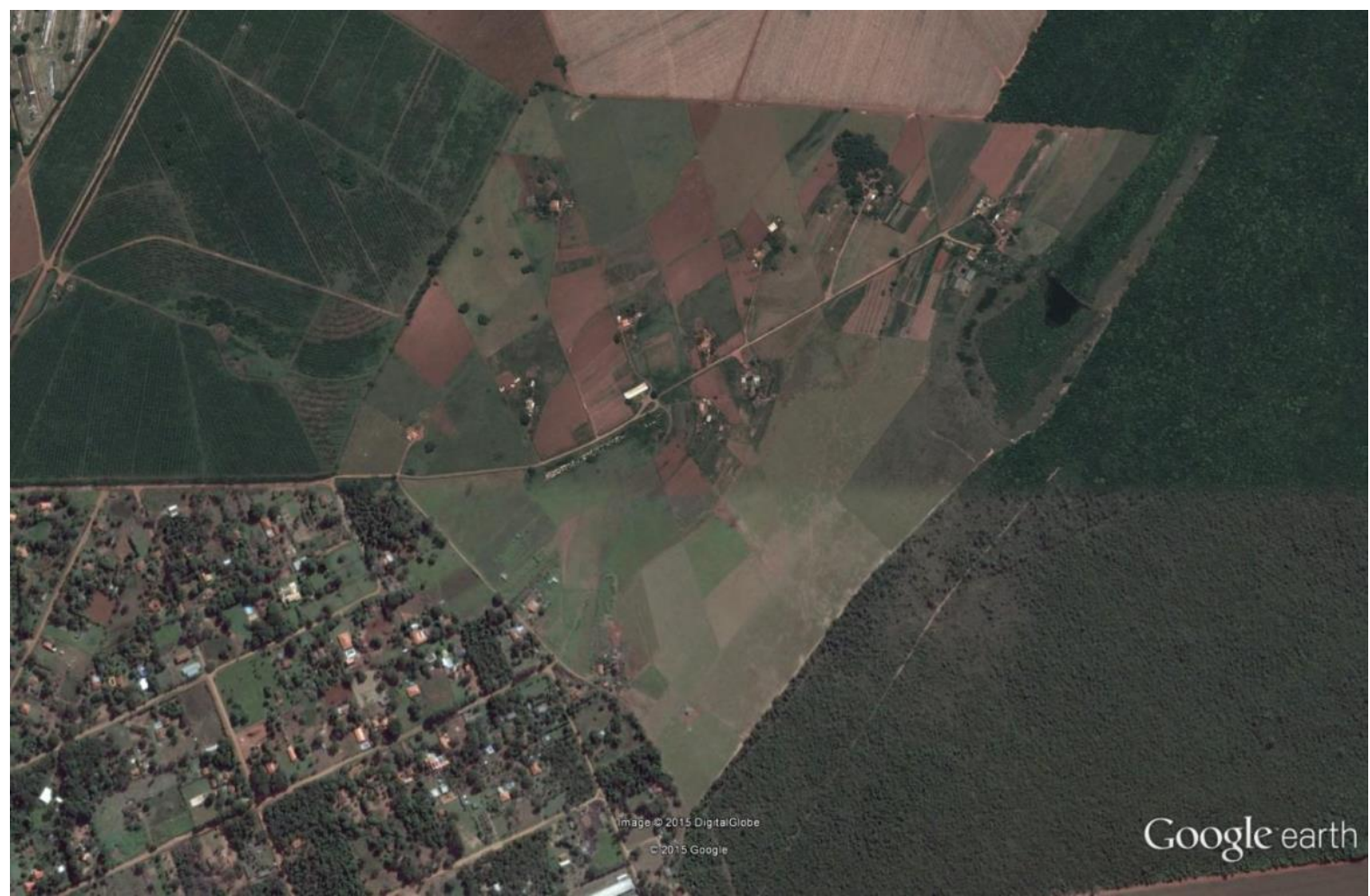

Figura 1: PDS Assentamento Santa Helena - região da Represa do 29, São Carlos, SP. Fonte: Google Earth (2015).

Dentre as políticas públicas mais importantes do Governo Federal, destacamos a efetividade no PDS/Assentamento Santa Helena do Programa Nacional de Fortalecimento da Agricultura Familiar (PRONAF), criado em 1995 para o fortalecimento das atividades produtivas geradoras de renda das unidades familiares de produção, com linhas de financiamento rural adequada à sua realidade; e do Programa de Aquisição de Alimentos (PAA), criado em 2003, que visa apoiar a comercialização agropecuária dos agricultores familiares, estimulando a produção de alimentos, bem como facilitar o acesso a esses alimentos pelas famílias em situação de IA (LEÃO; MALUF, 2012).

$\mathrm{Na}$ área social, destacaram-se o Programa Bolsa Família (PBF), que é um programa de transferência de renda, com condicionalidades nas áreas de educação, saúde e assistência social, às famílias em situação de pobreza extrema (BRASIL 2016); e do Programa Nacional de Alimentação Escolar 
(PNAE), no qual a renda é destinada à aquisição de alimentos, visando aumentar a frequência escolar (LEÃO; MALUF, 2012).

Outros programas também são importantes no assentamento para a promoção de SAN: o Programa Nacional de Apoio à Captação de Água de Chuva e outras Tecnologias Sociais (Programa Cisternas), implementados através de parcerias com Órgãos governamentais, como a Empresa Brasileira de Pesquisa Agropecuária (Embrapa), através de suas unidades de pesquisa localizadas em São Carlos, Embrapa Pecuária Sudeste e Instrumentação que, através de convênio de cooperação técnica com a OSCIP Iniciativa Verde, vinculada à Petrobras através do Programa "Plantando Águas", permitiram a instalação de tecnologias sociais que promovem a saúde humana e a proteção ao meio ambiente (Clorador, fossa séptica biodigestora e jardim filtrante, na maioria dos lotes) (OSCIP INICIATIVA VERDE, 2015); além da Universidade Federal de São Carlos (UFSCar) e da Universidade de São Paulo (USP) que, através da ENACTUS, promoveram as cestas semanais de produtos orgânicos (ENACTUS, 2015), e a Universidade de Araraquara (UNIARA), com a implantação de sistemas agroflorestal (SAF) (ARRUDA, 2016).

\section{Procedimentos metodológicos}

A pesquisa, caracterizada como estudo de caso3, utilizou métodos descritivos, de objetivo exploratório, com abordagens quantitativas e qualitativas. O objetivo exploratório da pesquisa partiu do levantamento bibliográfico de dados secundários (livros, artigos de periódicos e de eventos, dissertações, teses e outros documentos) do objeto de estudo e dos sujeitos envolvidos a fim de ampliar o mais detalhado possível seu conhecimento.

A coleta de dados primários foi realizada no PDS Assentamento Santa Helena, município de São Carlos-SP, em área de preservação permanente (APP) e de reserva legal (RL), com 14 famílias de agricultores familiares, tendo início em abril de 2015 e término em março de 2016. Primeiramente, foram realizados diálogos com as famílias e anotações em Diário/Caderno de campo (guiadas por um roteiro) e, posteriormente, foram aplicados formulários validados contendo os métodos da EBIA (SEGALL-CORRÊA; MARIN-LEON, 2009) e do Índice UFSCar para a SAN de agricultores familiares (ALMEIDA et al., 2015).

\section{Resultados e discussões}

Foram incluídas neste estudo 14 famílias e avaliadas mais de 100 variáveis relacionadas aos aspectos demográficos, socioeconômicos, ambientais, de percepção e hábitos alimentares das famílias, de forma quantitativa e qualitativa, sendo algumas variáveis analisadas de forma complementar com as observações de campo, como as trajetórias de vida, a solidariedade entre as famílias, a cultura alimentar, os meios de produção, entre outras.

De acordo com Arruda (2017), durante pesquisa de campo, foi observado que todas as famílias são beneficiárias do Programa de 
Assentamentos Rurais; 78,57\% (11) dos lotes estão sob a responsabilidade formal da mulher, enfatizando a importância da questão de gênero; e 57,14\% (8) participam de programas de SAN (PAA e PNAE), inserção social ocorrida em agosto de 2015 após reunião pacífica entre os agricultores e representantes da Secretaria da Agricultura e Abastecimento do município de São Carlos, do INCRA, através do Instituto Biosistêmico (IBS), Órgão terceirizado pelo INCRA e e a conselheira em exercício do Conselho Regional de Segurança Alimentar e Nutricional (CRSANS)/Central/SP.

Em relação ao $\mathrm{PBF}, 28,57 \%$ (4) das famílias entrevistadas são beneficiárias do programa. Verificou-se durante a aplicação do questionário EBIA/Índice UFSCar que nenhuma família era beneficiária do Programa de Apoio à Conservação Ambiental (Bolsa Verde), tendo como justificativa a ausência de moradores do PDS Santa Helena em situação de extrema pobreza.

Observou-se também que 78,57\% (11) das famílias destinam o lixo doméstico na caçamba disponibilizada pela Prefeitura e que fica distante cerca de $3 \mathrm{~km}$ do Assentamento; $57,14 \%$ (8) queimam o lixo e/ou enterram na propriedade; 92,86\% (13) não possuem uma destinação do lixo para o lixo reciclável; e 78,57\% (11) destinam o lixo orgânico para compostagem.

Quanto ao tipo de esgoto, notou-se que 78,57\% (11) das famílias possuem rede coletora de esgoto e/ou água de chuva (Cisternas) e caixa de gordura, sendo que 64,29\% (9) possuem fossa séptica biodigestora (FSB)11; $7,14 \%$ (1) possuem fossa séptica (em substituição à "fossa negra" ou rudimentar) e que $28,57 \%$ (4) ainda utilizam as fossas negras ou rudimentares; 35,71\% (5) têm jardim filtrante (JF); e apenas 7,14\% (1) fazem a prática de reciclagem de seu lixo doméstico com venda esporádica.

A respeito do tratamento de água, todas as famílias possuem filtro comum de cerâmica (pote) e que a maioria possui caixa d'água $(71,43 \% ; 10)$ e clorador Embrapa12 (64,29\%; 9).

Em relação ao acompanhamento da saúde, verificou-se que transcorridos 11 anos de instalação do PDS, nenhuma família do Santa Helena recebeu visita de agentes comunitários de saúde (ACS) ou de assistentes sociais da Prefeitura. Somente em meados de 2015, por iniciativa da ENACTUS, os agricultores e suas famílias puderam fazer tratamento dentário.

Após aplicação do questionário EBIA, ficou caracterizado que 57,14\% (8) das famílias estão em situação de segurança alimentar (SA); $28,57 \%$ (4) com insegurança alimentar moderada (IAM) e 14,29\% (2), com insegurança alimentar leve (IAL). Somando-se o IAM e IAL, o total de insegurança alimentar equivale a 42,86\% (6). Buscou-se, através da aplicação do método Índice UFSCar para Segurança Alimentar, conhecer as causas que levaram essas famílias ao estágio de insegurança alimentar.

Em relação a informações sobre produção, subsistência e autoconsumo das famílias, foi observado que $64,29 \%$ (9) das famílias têm uma produção agrícola diversificada (mais de 3 produtos). Dessa produção, a maioria das famílias utiliza para autoconsumo $(92,31 \%$; 13) e vende via Rede Agroecológica Santa Helena $(61,54 \% ; 8)$. Além disso, cerca de $38 \%$ destinam para venda ao mercado tradicional, $46 \%$ ao mercado institucional, $23 \%$ trocam/doam e $46 \%$ vendem diretamente nos lotes. Apenas uma agricultora 
vende seus hortifrútis nas ruas do município de São Carlos. Com relação à produção pecuária, $50 \%$ (7) das famílias têm uma produção diversificada (mais de 3 animais), 28,57\% (4) não diversificam e 21,43\% (3) não produzem. Dentre os que produzem, o destino da produção é o autoconsumo, especialmente o leite, para todas as famílias e venda direta no lote para $72,73 \%$ (10) delas.

As informações sobre a caracterização do trabalho e da renda das famílias são apresentadas na Tabela 1 . Em relação à renda agrícola das famílias, observa-se um valor médio aproximado de $\mathrm{R} \$ 970,00$ (novecentos e setenta reais) com DP de $\mathrm{R} \$ 2057,62$ (dois mil e cinquenta e sete reais e sessenta e dois centavos), sendo que a maior renda observada é de $\mathrm{R} \$ 8000,00$ (oito mil reais) e a menor, zero. Para a renda não agrícola, a média observada é de $\mathrm{R} \$ 928,57$ (novecentos e vinte e oito reais e cinquenta e sete centavos), com DP de $\mathrm{R} \$ 1541,60$ (um mil, quinhentos e quarenta e um reais e sessenta centavos) e a renda máxima de $\mathrm{R} \$ 5000,00$ (cinco mil reais) e a mínima, zero. Sobre outras rendas recebidas pelas famílias, nota-se um valor médio de $\mathrm{R} \$ 534,50$ (quinhentos e trinta e quatro reais e cinquenta centavos). A porcentagem da renda agrícola para a renda total varia de 0 a $100 \%$, com valor médio de $36 \%$.

Tabela 1: Tipos de renda.

\begin{tabular}{crrrrr}
\hline $\begin{array}{c}\text { (R\$) das famílias } \\
\text { do PDS Santa } \\
\text { Helena. }\end{array}$ & Média & Desvio Padrão & Mín. & Mediana & Máx. \\
\hline Renda agrícola & 970,43 & 2057,62 & 0,00 & 545,00 & 8000,00 \\
\hline Renda não agrícola & 928,57 & 1541,60 & 0,00 & 125,00 & 5000,00 \\
\hline Renda outros & 534,50 & 442,78 & 0,00 & 597,50 & 1576,00 \\
\hline Renda total & 2433,50 & 2055,49 & 780,00 & 1595,00 & 8000,00 \\
\hline $\begin{array}{c}\text { Renda agrícola para } \\
\text { renda total (\%) }\end{array}$ & 0,36 & 0,33 & 0,00 & 0,41 & 1,00 \\
\hline
\end{tabular}

Fonte: Elaborado pelos autores (2016).

As rendas obtidas através das vendas de produtos orgânicos ao mercado institucional (PAA e PNAE) do município de São Carlos que se deram a partir de novembro/2015, cujos pagamentos somente a partir de janeiro/2016. Para este fim, os agricultores do PDS/Santa Helena participaram de Chamadas Públicas, por dispensa de licitação, sendo que cumpriram com os pré-requisitos do Edital respectivo, incluindo qualidade dos produtos. No período de agosto a novembro/2015, os agricultores preocuparam-se com a regularização da documentação pertinente de cada lote, sob sua responsabilidade, tornando-os hábeis à comercialização.

Recentemente, para verificar a evolução da renda agrícola referente ao período de 2016 a 2018, junto aos Programas do Governo, PAA e PNAE, utilizou-se análise descritiva, etapa inicial de apresentação de resultados para qualquer tipo de procedimento utilizado para descrever e resumir informações (GOODMAN, 1965). 
Os dados fornecidos pelo Departamento de Agricultura da Secretaria de Agricultura e Abastecimento do município de São Carlos (Tabela 2), foram gerados no Excel. De acordo com o Gráfico 1, observa-se que, de 2016 a 2017, os valores totais comercializados, tanto para o PAA, quanto para o PNAE, aumentaram em média cerca de $30 \%$. Além disso, nos quatro primeiros meses de 2018, o PAA já tinha atingido aproximadamente $23 \%$ do valor adquirido no ano anterior. Não foram obtidos ou informados os valores de 2018 referentes ao PNAE. Observa-se ainda que o valor da comercialização do PNAE é mais baixo que o valor comercializado ao PAA, tanto para 2016 como para 2017.

Tabela 2: Comercialização PDS/Assentamento Santa Helena (PAA e PNAE), anos $2016-2018$.

\begin{tabular}{r|c|c|c}
\hline \multicolumn{4}{c}{ COMERCIALIZAÇÃO PDS/Assentamento Santa Helena } \\
\hline $\begin{array}{c}\text { PERÍODO } \\
\text { Nov- }\end{array}$ & PAA (R\$) & PNAE (R\$) & $\begin{array}{c}\text { No }^{\circ} \\
\text { AGRICULTORES }\end{array}$ \\
\hline 2016 & - & - & 4 \\
\hline 2017 & $24.388,22$ & $23.864,73$ & 7 \\
\hline $\begin{array}{c}\text { Jan a } \\
\text { abril/2018 }\end{array}$ & $\mathbf{3 5 . 9 0 4 , 5 6}$ & $33.156,10$ & 7 \\
\hline
\end{tabular}

Fonte: Departamento de Agricultura da Secretaria de Agricultura e Abastecimento de São Carlos, SP (2018).

\section{Gráfico 1: Gráfico da evolução dos valores de comercialização PDS Santa Helena.}

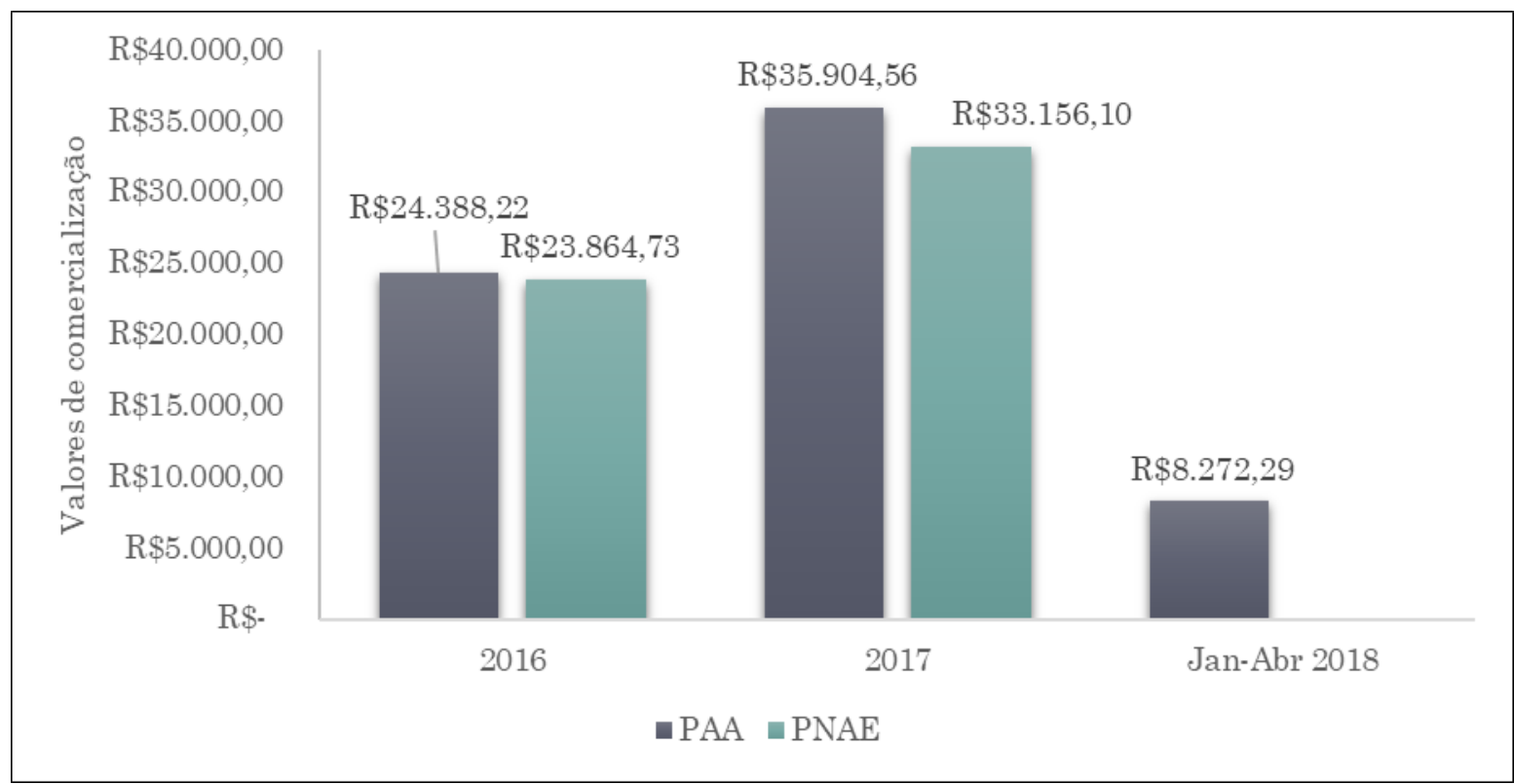

Nota: Análise estatística - Data Set Consultoria.

Fonte: Departamento de Agricultura/Secretaria de Agricultura e Abastecimento/São Carlos, SP (2018). 
Em relação às vendas por lote, verifica-se no Gráfico 2 que a mediana de vendas por lote foi de $R \$ 3.609,72$ em 2016 e de $R \$ 6.452,11$ em 2017, não tendo destaque para nenhum lote com comercialização mais alta que os demais. Já no PNAE, em 2016 a mediana foi de $R \$ 2.672,62$ e em 2017, $\mathrm{R} \$ 5.297,37$ de comercialização, com destaque para o Lote 2 que teve maior comercialização do que os demais, nos dois anos consecutivos (Gráfico 3).

\section{Gráfico 2: Comercialização PAA (2016/2017).}

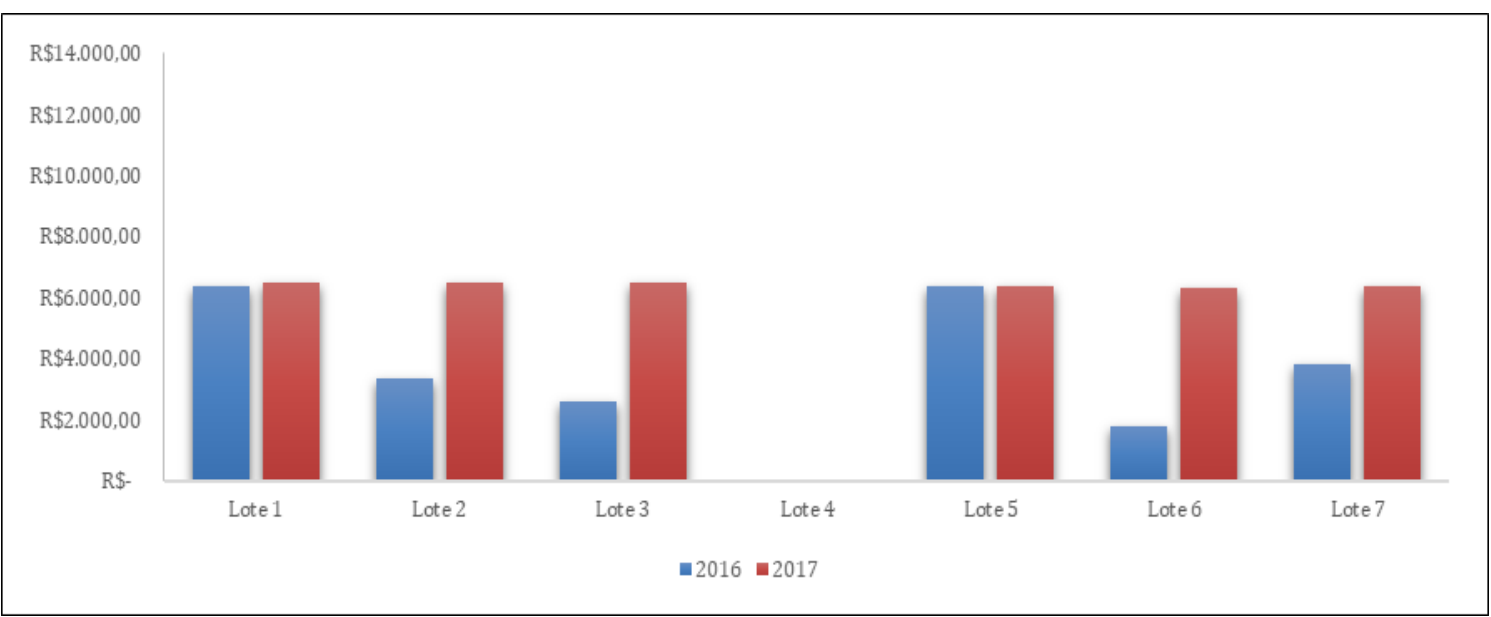

Nota: Análise estatística - Data Set Consultoria.

Fonte: Departamento de Agricultura/Secretaria de Agricultura e Abastecimento/São Carlos, SP (2018).

\section{Gráfico 3: Comercialização PNAE (2016/2017).}

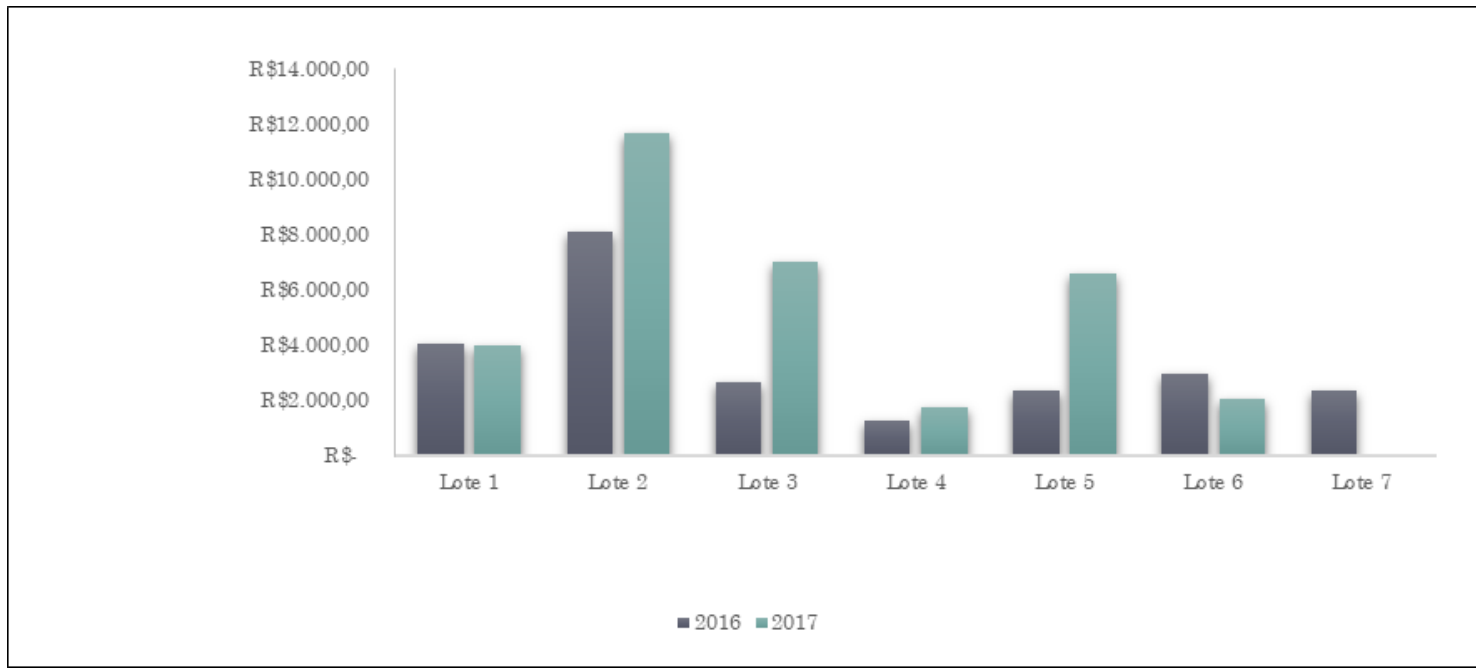

Nota: Análise estatística - Data Set Consultoria.

Fonte: Departamento de Agricultura/Secretaria de Agricultura e Abastecimento/São Carlos, SP (2018).

Os dados acima comprovam a importância e a necessidade de continuidade de ações efetivas de acompanhamento das políticas públicas 
relacionadas à comercialização da produção de um assentamento, objetivando sanar os entraves de inclusão social e a erradicação da insegurança alimentar dos agricultores e suas famílias, que lutam pelo seu espaço e reconhecimento como produtores de alimentos saudáveis para si e seus consumidores, em cumprimento ao que determina os cinco grandes Eixos sobre o conceito amplo de segurança alimentar, preconizados pela FAO/ONU (saúde, higiene, ecológico, autenticidade e solidariedade).

\section{Considerações finais}

A abordagem inicial ao conceito e evolução da SAN mostrou que populações inseridas em contexto de vulnerabilidades sociais demandam uma rede de segurança ou proteção social, de políticas e programas que abarquem todos os aspectos relacionados ao conceito amplo de SAN. Desse modo, é necessário que trabalhos voltados à ótica da SAN, principalmente em comunidades rurais, busquem informações relacionadas a todos os aspectos, incluindo trajetória de vida, luta pela terra, costumes, origem das famílias, questões relacionadas à problemática ambiental territorial, entre outros.

Este trabalho foi pioneiro em atuar com a temática de SAN atrelada à dinâmica de vida e à caracterização social, econômica e de hábitos alimentares do PDS Santa Helena, município de São Carlos/SP, contribuindo com outras pesquisas já realizadas no universo de estudo, principalmente sobre as trajetórias de vida das famílias, culturas, relações de gênero, solidariedade como estratégia familiar, moradia, renda, trabalho, produção, comercialização, entre outros aspectos fundamentais tanto para os próprios moradores como para os demais atores locais em relação ao aprimoramento ou implementação de novas políticas públicas.

O método Indice UFSCar, o qual corrobora com a EBIA, permitiu que aferições fossem possíveis também no aspecto socioambiental, com relação ao termo sustentabilidade (visto por alguns autores como um termo presente somente em discursos políticos), a efetividade de sua definição que engloba o desenvolvimento social, econômico e da preservação ambiental, promovendo a inclusão social, justiça socioambiental, preservação e conservação ambiental. Permitiu também que aspectos considerados comuns fossem diagnosticados e mensurados, como a questão "destino dado ao lixo doméstico", inserção da variável "compostagem", prática comum para a maioria dos agricultores e suas famílias, importante para o incremento da produção orgânica.

No item "tipo de esgoto sanitário", foi possível o diagnóstico de que mais da metade dos domicílios estavam contemplados com cisternas, que permitem a coleta de água de chuva e sua reutilização; a rede coletora de esgoto do município não existe, porém, talvez haja a necessidade futura da instalação de uma ETE; boa parte dos domicílios foi contemplada com fossa séptica biodigestora, tecnologia de baixo custo que permite o tratamento das águas do vaso sanitário (dejetos humanos) tornando-os livres de coliformes fecais, evitando dessa forma, a contaminação do meio ambiente local (solo, água e águas subterrâneas); bem como alguns domicílios tratam as "águas cinzas", assim denominadas porque tratam as águas do chuveiro (banho), da 
pia da cozinha e do tanque/pia de lavar roupas, que contêm detergente e vários tipos de sabão, respeitando aos eixos 2 e 3 da SAN, a promoção da saúde humana, com forte apelo de respeito ao meio ambiente ecológico ou orgânico, sem riscos de agentes tóxicos ou patogênicos.

Com relação ao tratamento da água em cada lote, item que não estava contemplado no questionário da UFSCar para SAN (sendo uma contribuição para a melhoria do Índice), deveria ser o primeiro item a ser diagnosticado e anteceder ao de "coleta de lixo" e "tipo de esgoto" existente no domicílio. Houve a inserção desta variável como "outras formas de tratamento da água", que permitiu o detalhamento do total de moradores com posse de filtros comuns ("potes") e mais da metade das famílias com caixa d'água e clorador, itens estes importantes que permitem tornar a água potável, própria para o consumo humano e higienização de produtos hortifrútis, obedecendo ao que preceitua os eixos 1 e 2 da SAN, saúde e higiene.

Em relação à saúde, uma informação que surpreendeu de forma pejorativa foi que, em 11 anos de sua implantação, o PDS em estudo nunca recebeu a visita de agentes comunitários de saúde do município, dado importante para ser revisto pelos atores públicos locais, uma vez que estes possuem papel fundamental enquanto agentes da atenção primária à saúde com o foco na família, sendo necessária sua presença neste universo devido, principalmente, às situações singulares que a dinâmica rural apresenta. Adicionalmente, ainda dentro da amplitude da saúde, outro fato observado foi o consumo exagerado de óleo de cozinha, bem como a presença de obesidade em todos os membros de uma família (mesmo que diagnosticada de uma forma perceptiva pela pesquisadora). Tais resultados mostram a carência de se olhar para questões não menos necessárias ao conceito amplo de SAN, ou seja, ao estado nutricional, psicológico e à educação nutricional demandada e ofertada nesta comunidade e neste território. Nesse sentido, trabalhos voltados ao eixo saúde seriam importantes para subsidiar outros trabalhos sobre SAN, bem como o próprio Índice UFSCar para a SA, possibilitando ricas discussões sobre hábitos alimentares (fortemente cristalizados neste estudo pelas questões culturais e de origem das famílias), soberania alimentar (poder de decidir sobre os hábitos alimentares), educação alimentar (orientação) e estado nutricional (equilíbrio entre quantidade e tipo de alimentos ingeridos, nutrientes e energia).

A informação mais difícil de ser obtida durante os diálogos foi a questão da IA (diagnosticada pelo questionário da EBIA). Foi perceptível a mudança comportamental após a inserção às perguntas contempladas pelo Índice UFSCar, pois permitiu que as agricultoras e os agricultores ficassem mais seguros e à vontade para responder tais questões, que ainda causam muito constrangimento e o retorno às lembranças de fatos dolorosos vivenciados durantes suas trajetórias de vida. Os sujeitos perceberam que outras variáveis poderiam estar interferindo ou promovendo a IA em seus domicílios. Isso permitiu maior aprofundamento a partir do cruzamento das questões relacionadas à SAN com outras variáveis encontradas.

Foi elaborado o gráfico de migração das famílias, bem como o índice de escolaridade e trabalho, importantes variáveis que têm influência com a renda 
agrícola e não agrícola total dos domicílios, pois o fato de que ainda existem pessoas que não sabem ler e nem escrever faz com que os agricultores que não participam do mercado institucional e nem do tradicional, tenham menor índice de renda agrícola, trazendo reflexos negativos para sua inclusão social e melhoria da qualidade de vida. Apenas três agricultores trabalham fora dos lotes fazendo "bicos" nos finais de semana no condomínio de chácaras vizinho ao assentamento, sendo considerada a pluriatividade como positiva para a estratégia de permanência destes nos lotes, pois permite um ganho de renda considerada como não agrícola, quando da aplicação do Índice.

Oito produtores de orgânicos participam da Rede Agroecológica Santa Helena que, após sua implementação, contribuiu para que homens e mulheres permaneçam por maior tempo nos lotes dedicando-se à produção agrícola, sendo que o maior índice de mulheres que trabalham nos lotes, o que fortalece a questão de gênero, pois antes da instalação da Rede, sete trabalhavam fora dos lotes (cinco homens e duas mulheres). A maioria dos moradores também participa das atividades sociais da Associação dos Produtores "Nova Santa Helena".

Em relação às informações sobre produção, subsistência e autoconsumo, mereceu destaque a produção destinada ao autoconsumo, que é orgânica e de boa qualidade. A maior renda por produção agrícola cabe à minoria dos produtores pelo fato destes atenderem com regularidade ao mercado institucional (PAA e PNAE) e participarem de todas as feiras do município. Mais da metade dos produtores que diversificam sua produção agrícola orgânica não estavam contemplados pelo mercado institucional, fato que ocorreu somente após a intervenção da CRSANS/Central e do IBS (representante do INCRA), junto à SMAA, para a (re)inclusão social desses agricultores neste mercado.

O excedente de produção foi uma importante variável encontrada e que permitiu a percepção do pressuposto de ausência de organização da produção (gestão) e a constatação de que mais da metade de produtores de orgânicos não estavam sendo contemplados pelos mercados institucional e tradicional, contrariando ao exigido pelos eixos 4 e 5 da SAN, em relação à autenticidade (saber fazer, valorização da forma de produção tradicional, quanto à origem dos alimentos) e à solidariedade (os valores morais ao consumo consciente e de agregação de valor aos produtos agrícolas social e ecologicamente corretos, advindos de assentamentos rurais ou de pequenas propriedades e sem utilização da mão-de-obra infantil).

Nas questões socioeconômicas relacionadas à produção, fica aqui a sugestão de inclusão no Índice UFSCar de itens que abordem questões sobre as tecnologias instaladas para incentivo à produção orgânica, importantes elementos para a conversão agroecológica, como os SAF e agrossilvipastoril, a utilização do efluente da FSB como biofertilizante no cultivo de milho (Bokashi), o sistema de irrigação, que também protegem o meio ambiente (solo e água), ou seja, a forma de instalação, as parcerias, os recursos provenientes de programas ou de políticas públicas, o tempo de implantação e os índices de produção antes e após instalação são algumas questões a se colocar. 
O Índice UFSCar poderá avançar no aprimoramento de políticas públicas que têm por objetivo apoiar e fortalecer a produção dos pequenos produtores, como o PRONAF, apontando os gargalos existentes, como por exemplo, os empréstimos feitos para aumento da produção animal, que neste caso, por mortes acidentais, não exime os produtores da dívida estabelecida.

Por fim, nas questões socioambientais, este trabalho poderá subsidiar informações, inovação ou incremento às políticas públicas voltadas ao saneamento básico rural, através do Plano Nacional de Saneamento Básico (PLANSAB), vinculado ao MMA, na esfera federal e sob a coordenação do Ministério das Cidades, para a instalação de ETE nos PDSs, como acompanhamento das políticas de preservação e recuperação ambiental no território dos municípios, subsidiando ao COMDEMA local sobre as necessidades básicas de saúde, qualidade de vida e exercício da cidadania aos produtores, moradores em assentamentos na modalidade PDS, bem como a atuação dos órgãos locais como parceiros.

\section{REFERÊNCIAS}

ALMEIDA, Luiz Manoel de Moraes Camargo; PAULILLO, Luiz Fernando Oriani; BERGAMASCO, Sônia Maria Pessoa Pereira.; FERRANTE, Vera Lúcia Silveira Botta. Políticas Públicas, redes de segurança alimentar e agricultura familiar: elementos para construção de indicadores de eficácia. Estudos Sociedade e Agricultura, Rio de Janeiro, v.14, n. 2, p. 205-235, 2006.

ALMEIDA, Luiz Manoel de Moraes Camargo. Estrutura de Governança e Gestão das Redes e Programas de Segurança Alimentar: Análise Comparativa entre Municípios Paulistas. 2008. Relatório técnico (Bolsa de PósDoutorado no país) - Faculdade de Engenharia Agrícola - UNICAMP, Campinas. 2008.

ALMEIDA, Luiz Manoel de Moraes Camargo; PAULILLO, Luiz Fernando Oriani; MAIORANO, Alexandre Cristovão; LOUZADA, Francisco. Índice UFSCar de segurança alimentar para agricultores familiares. Revista de Política Agrícola, v. 24, n. 14, 2015.

ALY JUNIOR, Osvaldo. Projetos de Desenvolvimento Sustentável e os desafios na construção de novas políticas de assentamentos. Retratos de assentamentos, v.19, n.1, 2016.

ARRUDA, Terezinha Pinto. Avaliação da segurança alimentar e nutricional de agricultores familiares do projeto de desenvolvimento sustentável Santa Helena de São Carlos-SP. 2016. 156f. Dissertação (Mestrado em Desenvolvimento Territorial e Meio Ambiente) - Universidade de Araraquara, Araraquara.

BELIK, Walter. Perspectivas para segurança alimentar e nutricional no Brasil. Saúde e Sociedade, v.12, n.1, p.12-20, 2003. 
BRASIL. Palácio do Planalto. Relatório Final: declarações e proposições da $4^{a}$ Conferência Nacional de Segurança Alimentar e Nutricional. Alimentação Adequada e Saudável: Direito de Todos. Brasília, DF: CONSEA: 2011.

BRASIL. Ministério da Agricultura, Pecuária e Abastecimento - MAPA. Controle Social. Organização de Controle Social. Procedimentos das OCS para Cadastramento. Brasília, DF: MAPA, 2007. Disponível em: http://www.agricultura.gov.br/portal/page/portal/InternetMAPA/pag. Acesso em: dez. 2016.

CARDOZO, Daiane Roncato. Renda, consumo alimentar e estado nutricional como indicadores complementares à insegurança alimentar e nutricional no Programa Bolsa Família. (Tese de Doutorado em Alimentos e Nutrição). Araraquara: UNESP, 2016. Tese (Doutorado em Nutrição) - Universidade Estadual de São Paulo, Araraquara, 2016

ENACTUS. Relatório do Projeto Geração Helena - desenvolvendo ações socioambientais. São Carlos: Escola de Engenharia de São Carlos (EESC), Universidade de São Paulo (USP), 2015.

GOODMAN, Richard. Aprenda sozinho Estatística. São Paulo: Pioneira. Universidade de São Paulo, 1965.

GUERRERO, Iris Cecilia Ordoñez. (In)segurança alimentar no Assentamento Rural Horto Vergel - Mogi Mirim/SP. Campinas: Unicamp, 2009. Originalmente apresentada como monografia, Faculdade de Engenharia Agrícola, Universidade Estadual de Campinas, Campinas, 2009.

GUERRERO, Iris Cecilia Ordoñez. Reforma agrária e segurança alimentar em assentamentos rurais: o caso do Horto Vergel, Mogi Mirim/São Paulo. 2014. (Tese de Doutorado em Planejamento e Desenvolvimento Rural Sustentável), Faculdade de Engenharia Agrícola, Universidade Estadual de Campinas, Campinas, 2014.

INSTITUTO BRASILEIRO DE GEOGRAFIA E ESTATÍSTICA (IBGE). Pesquisa Nacional por Amostra de Domicílios - PNAD. Segurança Alimentar e Nutricional. Brasília: IBGE, 2013. 134 p.

LEÃO, Marília; MALUF, Renato Sérgio Jamil. A construção social de um sistema público de segurança alimentar e nutricional: a experiência brasileira. Brasília: ABRANDRH, 2012, 72p.

LOPES, Paulo Rogério; SARAVALLE, Caio Yamazaki; FRANCESCHINI, Guilherme; FREIRE, Leina. Problematização participativa da realidade local do assentamento agroecológico PDS Santa Helena - São Carlos/SP. In: 
SEMINÁRIO DE AGROECOLOGIA DA AMÉRICA DO SUL, 2014, Dourados, MS. Anais... Dourados, MS: 2014.

LOPES, Paulo Rogério. Transição agroecológica do assentamento Santa Helena - Problematização participativa da realidade local e "extensão" rural numa ótica do desenvolvimento rural sustentável. Campinas: UNICAMP, 2015. Originalmente apresentado como trabalho de conclusão de curso, Faculdade de Engenharia Agrícola, Universidade de Campinas, Campinas, 2015. 102p.

OSCIP "INICIATIVA VERDE". Ações do Plantando Águas no Assentamento Santa Helena - São Carlos, SP. São Carlos, 2015

LOPES, Paulo Rogério; SARAVALLE, Caio Yamazaki; FRANCESCHINI, Guilherme; FREIRE, Leina; SOUZA ESQUERDO, Vanilde Ferreira de. Projeto de desenvolvimento sustentável Santa Helena - São Carlos/SP: uma problematização das oportunidades, fraquezas, ameaças e fortalezas. Retratos de Assentamentos, v.19, n.1, 2016.

SEGALL-CORRÊA, Ana Maria; MARIN-LEON, Letícia. A Segurança Alimentar no Brasil: Proposição e Usos da Escala Brasileira de Medida da Insegurança Alimentar (EBIA) de 2003 a 2009. Segurança Alimentar e Nutricional, Campinas, SP, v. 16, n. 2, p. 1-19, 2009.

SILVA, Roberta Cristina. Manejo ecológico de pragas e doenças na cultura do tomateiro por meio do cultivo em sistema ecológico no assentamento Santa Helena, São Carlos, São Paulo. In: SEMINÁRIO DE AGROECOLOGIA DA AMÉRICA DO SUL, 2015, Dourados. Anais... Dourados, MS: 2015.

Recebido em: 10 de novembro de 2021.

Aceito em: 11 de novembro de 2021. Publicado em: 15 de dezembro de 2021. 